Vols. LXV-LXVI, January-June, July-December, 2019

ISSN 1607-2278 (Print), DOI : https://doi.org/10.3329/pp.v63i1-2.55959

\section{POSSIBILITY OF HARMONIZATION BETWEEN SCIENCE AND METAPHYSICS IN PHILOSOPHY}

\section{Md. Roqnuzzaman*}

\begin{abstract}
In respect of the sustainability of humankind on the presentday super motorized overwhelming Earth, harmonization between science and metaphysics becomes an ardent issue for current philosophical quests. On this topic, the underlying problem is, whether or not science and metaphysics could stay harmonically in a single system of knowledge. Science generally deals with necessary truths that inevitably connect sense experience, and conversely, metaphysics deals with super sensory aspects. So, there is a complication of compatibility between them. In this paper, it is expected to show that the harmonious co-existence of science and metaphysics is possible under the contemporary context of epistemological relativity, and this harmony is crucial for the furtherance of humankind on Earth.
\end{abstract}

\section{Introduction}

The issue of combining science and metaphysics stems, though not unquestionably, from some recent ideas such as the notion of constructive naturalism, the ontology of structures, quantum

* Associate Professor, Department of Philosophy, University of Rajshahi statistics of matter, the ontology of space and time, and the impression of part-whole relationship. Typically, the possibility of the blending of science and metaphysics emerges when the idea of epistemological certainty was questioned by some of the defendants of logical empiricism. In this regard, W. V. Quine, Donald Davidson, and Thomas Kuhn admit ontological relativity, indeterminacy thesis, and anti-foundational epistemology that cohere with the contemporary scientific theory of under-determination. On the other, Werner Heisenberg declares the uncertainty principle of quantum mechanics, and Albert Einstein proposes an alternative theory for upholding the challenge of the quantum-mechanical uncertainty principle which suggests the metaphysical nature of subatomic particles. Moreover, in recent times, scientificallyoriented philosophers Popper and Koyre try to attune science with metaphysics by the maxim of critical rationalism and by outstripping of the experiment. Meanwhile, after World War II, Henry Price raises the question of whether the philosophers played the proper role in saving humanity from the destruction of world wars or not? For him, eliminating metaphysics from philosophy, in the early twentieth century, is not admissible; in fact, it is intellectual suicide. In the upcoming days, it is yearned that philosophy as a holistic system of knowledge will be caring for humankind, insisting on the harmonization of science with metaphysics.

\section{Context of Metaphysics}

Metaphysics is the branch of philosophy that concerns the basic stuff of nature and life. It also deals with some concepts related to reality and human agency such as space and time, causation and causal connections, laws of nature, existence, 
essence, emotions, free will, aesthetics, and possible worlds. At the very beginning of philosophy, Aristotle treats metaphysics as the 'first philosophy'. By definition, metaphysics is the study of a sui generis possibility space; and is primarily aimed to uncover the sort of priority and dependence relations, holding between entities and facts that essentially characterize reality (Morganti: 2013, 29). Now metaphysics bargains with the problems of natural science also. In this regard, it has business to the relation between part and whole. Correspondingly, it can be treated as an a priori science by the representation of the deductive system through an axiomatic and geometric manner, and in this manner, it lies beyond the foundation of empirical sciences. Furthermore, metaphysics provides an effort to understand the rational structure of the universe, and in doing so, it works through the use of concepts with de-restricting empirical content. Contemporarily metaphysics is dichotomized as revisionary and descriptive; descriptive metaphysics wants to describe the real structure of our thought about the world, revisionary metaphysics wants to produce a better structure (Strawson: 1959, 9).

\section{Nature of Science}

Generally, science is defined as the study of the structure and behavior of the physical world through observation and experiment. But, in the early twentieth century, there happened a revolution in the domain of science. The revolution led to the idea that science remains in constant flux (Mikulinsky: 1977, 8). From this core notion of the methodical variability of science, the landmark idea of relativity has emerged, and it is believed that the ultimate triumph of science is the establishment of a firm belief in the idea of epistemological relativity. In the pose of epistemological relativity, there is nothing as eternal in science; scientific decisions are also erratic. The reality of science entails the idea that through scientific progress new science takes the place of old science and science becomes a process of an ever-changing entity with the synchronization of social changes (Islam: 2013, 226).

However, nowadays, science is dealt with in the facets of sociology. Sociologically oriented scientist John D. Bernal defines science as an institution, a method, a compilation of knowledge, and a powerful tool that can create immense influence on human consciousness and belief $(1965,31)$. He further settles the position of science as a part of the complete history of human society. Philanthropically, it is supposed that the need for the human being is the forerunner of science. In this regard, one of the expounders of the history of science, Jorge Sarton spells out: science began whenever and whatever human being tried to solve the innumerable problems of life $(1959,3)$. The problems of human life are the historical perspectives of science, and consequently, the historical perspectives of science connect with that of philosophy. Histories of science and philosophy are limited within the limit of the context of society.

\section{Points of Togetherness}

Though there is a dialectical relation between science and metaphysics, they can go together in search of knowledge. Science and metaphysics can be shown as complementary enterprises by endorsing the idea that science is not a pure instrumentalist approach only and by approving metaphysics as our knowledge of reality in general. However, the materialistic nature of science is commonly accepted, but in some aspects, 
science can also be exposed as an idealistic enterprise. In the early twentieth century, Arthur Eddington presents the idealistic nature of science. He remarks that in giving the name to his philosophy of physical science he is intended to name it as 'Selective Subjectivism'. For him, the domain of subjectivity has been extended as a consequence of our better understanding of quantum mechanics (1939, pp. viii, ix). Furthermore, in the contemporary era, it is revealed that some concepts of science are intangible, e.g., black holes, black body, point source of light, etc. Even in geometry, the ideal examples of a triangle and point are insubstantial, they are only conceptual. Meanwhile, Hilary Putnam describes that science and metaphysics are not dichotomized as that one is empiric and the other is a priori. Having confidence in the pragmatic verification maxim, Putnam asserts: for pragmatists the idea of verification was that it should apply to metaphysics so that metaphysics might become a responsible and significant enterprise (Macarthur: 2017, 23). For him, metaphysics goes next to science, and it deals with general matters as the abstract a posteriori knowledge (Puutnam: 1992). Later on, this idea is discussed much as Putnam's Kantianism; against Hume's charge, Kant rescues metaphysics by explaining the possibility of synthetic a priori knowledge.

Another prospect of togetherness stems from the fact that science is interacted with and interpreted by society. The history of science is the interaction between science and society. This interaction happens symmetrically between them, i.e., Science influences society and society influences science also. Science influences society mainly in two ways; one is making a change in the process of production, and the other is creating divergence with the existing philosophical theory
(Islam: 2013, 85). On the other, science is a part of the wider history of human society, it is the reality of changeability of the social world; social responsibility is the major concern of science.

Despite all the above, Newtonian physics and its innovative applications that deal with necessary truth make the critics accept that science had gone a vast more ahead in respect of philosophical enhancement. On the other, in early twentieth-century western philosophy, a group of empiricists tries to eliminate metaphysics from significant philosophy aiming to make philosophical truth as precise as scientific truth is. These empiricists are logical empiricists and they are called clarificatory philosophers especially for their attitude to the philosophy that severely emphasizes the clarification of concepts. To them, scientific truth is certain and perfect, and both science and philosophy should search for the necessary truth. From this milieu, a mishap happens in philosophy, it is tried to make philosophy detached from metaphysics to make it closer to science. Consequently, philosophy, for its essentialistic approach, becomes impassive to humanity.

\section{Possibility of Togetherness}

Generally, scientists claim that their theories are precise, valid, and logical, but they do not discuss the nature of certainty or the nature of logical validity, philosophers have to regulate those matters. Likewise, the problems of validity and argumentation are solely the problems of logic, and the problem of certainty is the problem of epistemology, and eventually, all these matters are the issues of philosophy. In recent times, in philosophy, the idea of epistemological certainty is challenged, and consequently, the possibility of 
compatibility between science and metaphysics arises. The challenge arises from the fact that science depends on collected data and scientists execute their functions of those data depending on hypothesis and inference. In this issue, the problem is that the achieved data are not certain. In most cases, there are epistemological limitations for observation and examination, so claiming the certainty of the data is insubstantial. Similarly, hypothesis and inference fall under suspicion for the sake of epistemological limitations. Furthermore, on the debate of epistemological certainty, most contemporary thinkers admit epistemological pluralism, i.e., there are multiple competing truths about the concepts and doctrines regarding humanities, social sciences, and theoretical physics also. The issue of togetherness of science and metaphysics results from these circumstances.

While taking the epistemological limitations in concern, W. V. Quine proves the deficiency of empiricism and its reductionism by his naturalistic epistemology. To explain the epistemological limit, he rejects sense data by saying that these are 'fancifully fanciless medium of unvarnished news' (1960, 2). Moreover, his naturalistic epistemology demands that the theoretical statements cannot be constructed only by observational consequences. Correspondingly, his ontological relativity and indeterminacy thesis cohere with the contemporary scientific theory of under-determination. Underdetermination says that many logically incompatible theories can be built on the same observational basis. Furthermore, the doctrine of under-determination of the theory claims that theories about the world transcend all possible observations of the world, and, different competing theories can be developed on the same observational basis. In a word, theories can be shown to be logically incompatible with one another, yet empirically equivalent. This naturalized epistemology and under-determination of scientific theory make the blending of science and metaphysics possible.

Like Quine, Donald Davidson also proclaims antifoundational epistemology. The ultimate claim of Davidson's anti-empiricist position is that we have no concept of nonfragmentary truth other than our ordinary and revisable judgments. There is no further notion of truth as the fitting of all these revisable judgments to an ultimate one. This antifoundational epistemology further claims that knowing the consequence of any observation in a given context depends on failing to question a mass of further observations. Following Quine's two dogmas of empiricism, Davidson further proclaims that modern empiricism has another dogma, and it is empiricists' belief in the distinction between conceptual scheme and empirical content (2001, 43). By razing this scheme-content distinction, Davidson provides a space for the possibility of blending between science and metaphysics. With analogous to epistemological anti-foundationalism, Thomas Kuhn endorses the contingency thesis, epistemological nominalism, and externalism that are pertinent to the paradigmshifting features of scientific revolutions. The notion of paradigm, which Kuhn presents, can sometimes be treated as metaphysical; since Kuhn equates paradigm with a set of beliefs, with a myth, with successful metaphysical speculation, and with a map. It is a metaphysical notion of an entity; rather than a scientific one. Sometimes paradigms can be called metaparadigms. Though the interpretation of the Kuhnian notion of paradigm as metaphysical is not fully agreeable, Kuhn himself emphasizes the psychological nature of the paradigm. By 
giving attention to the gestalt theory of psychology, Kuhn spells out: "what were ducks in the scientists' world before the revolution are rabbits afterward" $(1962,111)$.

Recently, metaphysical ideas have arisen in the field of quantum mechanics. It proclaims that subatomic particles arguably do not have the same sort of individuality as the particulars (Montwill \& Breslin: 2012, 120). In this regard, Werner Heisenberg adopts the uncertainty principle concerning the position and momentum of a particle that inspires the admittance of the metaphysical appeal to scientific conclusions. The uncertainty principle of Heisenberg admits that in a fundamental stage, the statement of the world is uncertain. The velocity and the position of a subatomic particle cannot be measured precisely. If the position is measured more precisely, the velocity will be vaguer as a consequence, and vice versa. As a result of the uncertainty principle, it appears that the nature of the fundamental elements of the world, quantum particles, is uncertain, and this uncertainty suggests the metaphysical attractiveness of the world. Albert Einstein proposes alternative theories for the challenge of the quantummechanical uncertainty principle, which is also a devotion to deterministic metaphysics (Hawking's lecture, 1999). Using the theory of relativity, Einstein proves that time is not a constant entity; time is different for different observers. He also disproves the notion of simultaneity by the special theory of relativity. We can eventually conclude that as a prominent scientist, Einstein also agrees with the idealistic attitude of McTaggart's declaration - 'time is not real'. Furthermore, in recent times, structural realism becomes popular in the context of Quantum physics, Quantum physics suggests the metaphysics of relations, i.e., the fundamental physical properties consist in certain relations instead of being intrinsic properties.

Meanwhile, some other philosophers of science try to show that there is a problem in the demarcation criterion between science and metaphysics. In this regard, Karl Popper claims that the problem concerning the demarcation between science and pseudo-science, as well as between science and metaphysics is closely related to the problem of induction (2002, 14-15). Depending on the limitations of inductive generalization, Popper presents a skeptic theory of science. To him, science does not rest upon solid bedrock. The bold structure of its theories rises, as it were, above a swamp. It is like a building erected on piles. The piles are driven down from above into the swamp, but not down to any natural or 'given' base (2002: 94). It implies that science can never demand that it has known the exact truth. He further holds that logical positivists' verifiability criterion of meaning is inappropriate because it not only excludes metaphysics but also excludes the scientific statements and theories of the universal laws of nature. These are no more reducible to observation datum than so-called "metaphysical pseudo propositions". Thus the criterion of meaning leads to the wrong demarcation of science and metaphysics (Popper: 1962, 261). Additionally, Popper delivers a view of critical rationalism, which provides a relative approach to science and society: dogmatism and relativism (Gattei: 2009, 1). In place of truth, relativism allows a scientific proposition to be considered as 'contingently true' if it has the potential to be shown false. Popper believes that knowing what is wrong offers more confidence than knowing what is right. We can get closer to the truth by negative instances, not by verification! It is misleading to build a 
general rule from observed facts (Taleb: 2007, 56). The contingency of the scientific proposition provides a middle way of relativism between science and society, and by adopting this contingency, Popper is standing at the brink between Physics and Metaphysics.

An alternative to Poppers' contingency, Paul Feyerabend endorses an anti-theoretic system of science; he terms it as an essentially anarchic enterprise (1975, 9). According to this theory, no scientist will fix himself within any methodological norm, and finally, he enjoys complete freedom for doing anything. Basically, theoretical anarchism is more human and progressive than its alternatives, based on law and order. Feyerabend further offers framework relativity for scientific theory and a method both of which deny the essence of scientific certainty. In this regard, he concludes that anything goes in science $(1975,14)$. Pertinent to Paul Feyerabend's framework-relativity and epistemological anarchism, Alexandre Koyre accepts that the scientific mind makes progress by outstripping the experimental devices, which shows the role of metaphysics in the theorization of science (1968, 80). Moreover, concerning the method of science, the heuristic method of Duhem style suggests that scientists should not follow any particular method; they should follow the method in which they feel comfortable to examine, and this empathy entails some hardcore metaphysical essentials for the scientific method. Subsequently, scientific-methodical alterations connect with metaphysical revolutions. Likewise, Joseph Agassi argues that as metaphysics is the coordinating agent in the field of scientific research so scientific problems are rooted in metaphysics (Agassi: 1975, 208). In these ways, in the late twentieth century, it is tried to show that science and metaphysics are connected within the matrix of the epistemological disorder. Like them, Joseph Agassi also claims that scientific problems are rooted in metaphysics (Agassi: 1975, 208).

Moreover nowadays a new approach to philosophy named post-modernity is developed with the unique characteristic of self-reflexivity, and this approach denies the modern notion of universality (Khan: 2002, 94). Subsequently, the notion of objective certainty and universality of any scientific theory is also discarded by this self-reflexivity. In this regard, one of the prominent postmodern thinkers, Rorty declares: the point of edifying philosophy is to 'keep the conversation going' rather than to find 'objective truth' (1979: 377). This idea of denying objectivity and 'keeping the conversation going' involve epistemological relativity which links the notion of social justification of epistemology. It is observed here that a new epistemology that concerns social justification is formed, and it is the social epistemology that focuses on how forms of knowledge (even science) often depend on social factors for their possibility.

\section{Science, Metaphysics, and Humanity}

Science and metaphysics can be connected at the point of humanity, since; the history of science depends on the history of society. The application of science, i.e., technology and its development are deeply connected with the development of humans and society. On the issue of the relationships among society, humans, and technology, Nuruzzaman spells out: the analysis of the metaphysics of technology is deeply hooked up with the analysis of the reality of humans and that of society (2016: 89). As a holistic subject, philosophy should incorporate 
science and metaphysics for the betterment of humankind. However, currently, scientific research and development are running mainly to achieve two goals; one is the centralization of world political power, and the other is the fulfillment of military needs. Science and technology have been used for extreme militarization aiming to achieve the highest profit. As a result, science becomes the part of the determination of political militarization that opens a door for neo-imperialism for the extreme military powered nations; and it leads to a catastrophe for humankind. The central question against political militarization and for the philosophizing of scientific inventions has arisen after World War II. In the article 'Clarity is not Enough,' Henry Price raises a question: whether the philosophers have played the proper role in saving humankind from the destruction of the world wars or not. For him, philosophy had somehow taken the wrong turning. Philosophers did not do their job to provide intellectual good or 'wisdom' to those who need it. He further adopts: apart from 'intellectual good,' philosophers had a severe interest in 'clarification.' They used clarification concepts to eradicate metaphysics, and unfortunately, through this enterprise, the significant problems about humanity and morality that grandly are philosophy were avoided, and hence philosophers could not show the right ways to avoid the wars. So, Price concludes, eliminating metaphysics from philosophy was not admissible; in fact, it was intellectual suicide (Price: 1963). In the wars, the human being has been treated as an impassive discrete individual, and humanism has been afflicted by dogmatic political essentialism. The humanity of this Earth has experienced the overwhelming application of scientific inventions at the wars. But, philosophy, bearing the aesthetic fusion of self and society, should guide science and politics to be compassionate to humanity by endorsing the issues of ethical norms, feelings, emotions, and sympathetic intellect as wisdom.

\section{Conclusion}

The philosophy that eliminates metaphysics to be closer to science will fail to bear the essence of humanity and consequently would be treated as pseudo-philosophy. Conversely, science, which is crazy to invent without philosophizing, must be harmful to humankind, and it would not be termed as science in the real sense of knowledge. Science shows us the glittering light of civilization, and, philosophy provides the epistemological foundations of that light by ontological supervision. In the upcoming days, it is desired that philosophy as a holistic system of knowledge will be caring for a gratified humankind on the Earth by crafting the harmonization of science with metaphysics.

\section{References}

Agassi, J. (1975). Science in Flux. Holland: D. Reidel Publishing Company.

Bernal, D. (1965). Science in History. Vol-1, England: Penguin Books.

Davidson, D. (2001). Subjective, Intersubjective, Objective. Clarendon: OUP.

Eddington, A. (1939). The Philosophy of Physical Science. Cambridge: The Cambridge University Press.

Esfeld, M. (2004). "Quantum Entanglement and a Metaphysics of Relations: Studies in History and Philosophy of Modern Physics 35B, pp. 601-617.

Feyerabend, P. (1975). Against Method. New York: New Left Books. 
French, S. \& Ladyman, J. (2003). "Remodeling Structural Realism: Quantum Physics and the Metaphysics of Structure". Syntheses 136, pp. 311-56.

Gattei, S. (2009). Karl Popper's Philosophy of Science: Rationality without Foundations. New York: Routledge.

Hawking, S. (1999). Does God Play Dice? Retrieved from https://www.hawking.org.uk/in-words/lectures/does-god-playdice.

Islam, S. (2013). Bigganer Darshan(1st \&2nd Volume). Dhaka: Kathaprokash.

Khan, G. A. (2002). Bijnaner Darshan. Dhaka: Jatiya Sahitya Prakash.

Koyre, A. (1968). Metaphysics and Measurement. Cambridge: Harvard University Press.

Kuhn, T. (1962). The Structure of Scientific Revolutions. Chicago: The University of Chicago Press.

Lakatos,, I. \& Musgrave, A. (1970). Criticism and the Growth of Knowledge. Cambridge: Cambridge University Press.

Macarthur, D. (Edited) (2017). Pragmatism as a Way of Life: The Lasting Legacy of William James and John Dewey. Cambridge: The Belknap Press of Harvard University Press.

Mikulinsky, S. (1977). History of Natural Science as a Science: Present State and Theoretical Problems. Moscow: USSR Academy of Science.

Montwill, A. \& Breslin, A. (2012). The Quantum Adventure. Does God Play Dice? London: Imperial College Press.

Morganti, M. (2013). Combining Science and Metaphysics: Contemporary Physics, Conceptual Revision and Common Sense. London: Palgrave Macmillan.

Nuruzzaman, M. (2016). Proyuktir Darshan (Philosophy of Technology). Dhaka: Jatiya Sahitya Prokash.
Popper, K. (1962). Conjectures and Refutations: The Growth of Scientific Knowledge. New York: Basic Books.

Popper, K. (2002). The Logic of Scientific Discovery. New York: Routledge Classics.

Price, H. (1963). "Clarity is not Enough". In Clarity is Not Enough: Essays in Criticism of Linguistic Philosophy. Edited by H D Lewis. London: Allen \& Unwin.

Putnam, H. (1992). Realism with a Human Face. Cambridge: Harvard University Press.

Quine, W V. (1960). Word \& Object. Cambridge: The MIT press.

Rorty, R. (1979). Philosophy and the Mirror of Nature. Princeton, NJ: Princeton University Press.

Sarton, G. (1959). History of Science, Vol-1. Baltimore: Carnegie Institute of Washington.

Strawson, P. F. (1959). Individuals. An Essay in Descriptive Metaphysics. London: Routledge.

Taleb, N. N. (2007). The Black Swan: The Impact of the Highly Improbable. New York: Random House. 